\title{
Primary Coronary Angioplasty and Stent Implantation in Acute Myocardial Infarction. Comparative Analysis of the In- Hospital Results in the CENIC/SBHCI Registry
}

\author{
Luiz Alberto Mattos, Amanda G. M. R. Sousa, Cantídeo C. N eto, André Labrunie, \\ Cláudia R. Alves, Jamil Saad, for CEN IC \\ ( $N$ ational Center of Cardiovascular Interventions) M embers.
}

São Paulo, SP - Brazil

\begin{abstract}
Objective - Comparative analysis of the in-hospital results after primary implantation of stents or coronary balloon angioplasty in patients with acute myocardial infarction $(M I)$.
\end{abstract}

Methods - CENIC (National Center of Cardiovascular Interventions) gathered data on 3,924 patients undergoing coronary angioplasty (in the primary form, without the previous use of thrombolytic agents) in the first 24 hours after a MI, during the period of 1996-1998. From these 3,924 patients, 1,337 (34\%) underwent stent implantation. We analyzed the success of the procedure and the occurrence of adverse cardiac events.

Results - In patients undergoing stent implantation there were more males $(77 \%$ vs $69 \%, p=0.001)$, previous by pass surgery $(6.3 \%$ vs. $4.5 \%, p=0.01)$, anterior MI and stent implantation in left descending artery (55\% vs. $48 \%$ vs. $p=0.009)$, and saphenous vein bypass grafts (3.3\% vs. $1.9 \%)$. the procedure was more succesful in the group of stents $(97 \% \mathrm{vs.} 84 \%, p=0.001)$ and reinfarction rate $(2.5 \mathrm{vs}$. $4 \%, p=0.002)$. The need for emergency revascularization was similar (1\% vs. $1.1 \%$, NS). Total in-hospital mortality was lower in stent group (3.4\% vs. 7. 2\%, $p=0.0001)$ and this effect was in patients Killip class III/V (19.5\% vs. $32.5 \%$, $p=0.002)$ because there was no difference in patients class $I / I I(1.7 \%$ vs. $2.8 \%, p=0.9)$.

Conclusion - Primary stent implantation in acute myocardial infarction showed better early results than balloon angioplasty alome.

Keywords: coronary angioplasty, stents, myocardial infarction

Sociedade Brasileira de Hemodinâmica e Cardiologia Intervencionista - São Paulo Mailing address: Luiz Alberto Mattos - Av. Jandira 550/121 - 04080-003 - São Paulo, SP, Brazil
Primary coronary angioplasty is one of the preferred methods of myocardial reperfusion performed without previous use of thrombolytic agents for the treatment of acute myocardial infarction ${ }^{1-5}$. It provides high levels of immediate arterial permeability with TIMI 3 optimal coronary flow ${ }^{6}$. When available, it is comprehensive and offers a significant reduction in the occurrence of major immediate events, such as reinfarction, stroke, and death ${ }^{3,5}$.

Results of randomized studies ${ }^{7,8}$, registries ${ }^{9}$, and consecutive series ${ }^{10}$, however, with the application of primary coronary angioplasty in acute myocardial infarction showed loss of immediate and late results in some subgroups of patients. In the in-hospital phase, the number of recurrent ischemias and reinfarctions was higher when suboptimal results were present (residual stenosis $>30 \%$ and significant coronary dissection); at 6 months, restenosis and reocclusion of the vessel initially treated were as high as $45 \%$ and, in $25 \%$ of the cases, new myocardial revascularization procedures were performed ${ }^{9,10}$.

Coronary stent implantation in acute myocardial infarction is arecent therapeutical option aiming tooptimizeimmediate andlate results ${ }^{11-17}$, based on evidence observed in elective patients ${ }^{18,19}$.

Our aim was to assess the in-hospital results of two techniques of percutaneous coronary revascularization in the acute phase of myocardial infarction: primary coronary stent implantation and conventional primary coronary balloon angioplasty. These two techniques are part of the national registry of procedures, CENIC (National Center of Cardiovascular Interventions), which belongs to the Sociedade Brasileira de Hemodinâmica e Cardiologia Intervencionista - SBHCI (Brazilian Society of Hemodynamics and Intervention Cardiology) ${ }^{20}$.

\section{Methods}

From 1996 to 1998, CENIC spontaneously received from its 153 associates the reports on 34,119 consecutive 
procedures of percutaneous coronary revascularization. These reports consisted of a standardized form of data collection providing clinical and angiographic profiles, as well as the description of the procedure performed, showing the early results and the occurrence of major complications in the in-hospital phase.

We analyzed the forms of angioplasty in the first 24 hours of an acute myocardial infarction without previous use of thrombolytic agents.

The patients were treated according to the specific routines of the several invasive cardiology services and the coronary stent implantation was performed according to the indication of the interventional cardiologist.

The data collection form showed that more than $90 \%$ of the patients received oral aspirin, ticlopidine, and intravenous heparin when stents were implanted. Abciximab was used in less than $5 \%$ of the patients.

All stent implantations were optimized with insufflations higher than $10 \mathrm{~atm}$. Quantification of ventricular function and of coronary stenoses was visual. The immediate success of the procedure (residual coronary stenosis < $50 \%$ and TIMI 2 or 3 coronary flow), occurrence of major complications, such as reinfarction, new coronary angioplasty, emergency surgery, and in-hospital deaths were analyzed comparing the two percutaneous forms of treatment.

In the statistical analysis, the continuous variables were assessed through the Student $t$ test or through the analysis of variance when the samples had the same number of data. Categorical variables were analyzed through the chi-square test or Fischer test, when necessary. Kwikstat method was employed for this purpose, with $\mathrm{p}<0.05$ considered statistically significant.

\section{Results}

From 1996 to 1998, 3,924 consecutive patients underwent primary angioplasty without previous use of thrombolytic agents in the first 24 hours following an acute myocardial infarction. Out of these 3,924 patients, 1,337 (34\%) underwent implantation of coronary stents, either in its primary form or due to suboptimal results of the coronary angioplasty, according to the indication of the interventionist. We observed that in 1996, stents accounted for $20 \%$ of the percutaneous procedures in acute myocardial infarction; in 1997 for $34 \%$, and in 1998 for $49 \%$ of the total procedures, an increase greater than $100 \%(\mathrm{p}=0.0001)$. Tables I and II show the clinical and angiographic profiles of patients who underwent stent implantation or primary coronary balloon angioplasty.

Among the patients undergoing primary stent implantation, we observed a higher number male of and patients with previous myocardial revascularization surgery. The mean age was similar, as was the presence of older patients.

The anterior descending artery was treated more frequently and significantly with stents, as were the saphenous vein bypass grafts. In regard to the complexity of the lesions treated in the acute phase of the myocardial

\begin{tabular}{|c|c|c|c|}
\hline \multicolumn{4}{|c|}{$\begin{array}{c}\text { Table I - Comparative analysis of the clinical profile of patients } \\
\text { undergoing primary stent implantation or angioplasty in acute } \\
\text { myocardial infarction (AMI) }\end{array}$} \\
\hline Variables $(\%)$ & Stent & PTCA & $\mathrm{p}$ \\
\hline Number of patients & 1337 & 2587 & - \\
\hline Female gender & 23.4 & 30.6 & 0.001 \\
\hline age (years) & 58.9 & 57.7 & 0.2 \\
\hline$>69$ years & 15.5 & 14.5 & 0.7 \\
\hline Previous coronary surgery & 6.3 & 4.5 & 0.01 \\
\hline Killip I/II & 90.5 & 85.4 & 0.0001 \\
\hline Killip III/IV & 9.5 & 14.6 & 0.0001 \\
\hline Anterior AMI & 55 & 48 & 0.009 \\
\hline
\end{tabular}

\begin{tabular}{|lccc|}
\hline $\begin{array}{l}\text { Table II - Comparative angiographic profile of the patients } \\
\text { undergoing stenting or percutaneous transluminal coronary } \\
\text { angioplasty (PTCA) in acute myocardial infarction (AMI) }\end{array}$ \\
\hline Variables (\%) & Stent & PTCA & $\mathrm{p}$ \\
\hline Vessel treated in AMI - AD & 55 & 48.4 & 0.009 \\
$\quad$ Saphenous vein & 3.3 & 1.9 & 0.001 \\
Multiarterial coronary disease & 42 & 45.6 & 0.08 \\
Extension of the lesion >10mm & 59 & 43 & 0.0001 \\
Lesions in bifurcations & 33 & 31 & 0.04 \\
Presence of thrombus & 64.5 & 72 & 0.001 \\
Previous stenosis (m) & 94 & 96 & 0.1 \\
\hline AD- anterior descending artery. & & & \\
\hline
\end{tabular}

infarction, those treated with stents were longer and more frequently located in bifurcations. Patients treated only with coronary angioplasty had lesions with more thrombi; the number of individuals with multivessel disease and the severity of coronary stenosis prior to the procedure, however, were similar.

Table III shows the immediate results and the occurrence of major complications. The success of the procedure was significantly greater when the patients received stents ( $97 \%$ vs $84 \%, p=0.001)$. Stents reduced the incidence of reinfarction $(2.5 \%$ vs $4 \%, \mathrm{p}=0.002)$ and of global in-hospital mortality $(3.4 \%$ vs $7.2 \%, \mathrm{p}=0.0001)$ more than $50 \%$. The necessity for new emergency revascularization procedures, either new coronary angioplasty or surgery, were similar for both techniques ( $1 \%$ vs $1.1 \%, \mathrm{p}=0.5)$.

\begin{tabular}{|c|c|c|c|}
\hline \multicolumn{4}{|c|}{$\begin{array}{l}\text { Table III - Immediate results of both procedures: success and } \\
\text { occurrence of major complications }\end{array}$} \\
\hline Variables $(\%)$ & Stent & PTCA & $\mathrm{p}$ \\
\hline Success $*$ & 97 & 84 & 0.001 \\
\hline Post stenosis (m) & 13.4 & 28.6 & 0.0001 \\
\hline Emergency surgery & 0.5 & 0.4 & 0.7 \\
\hline New PTCA & 0.5 & 0.7 & 0.5 \\
\hline Reinfarction & 2.5 & 4 & 0.002 \\
\hline Total death & 3.4 & 7.2 & 0.0001 \\
\hline \multicolumn{4}{|c|}{$\begin{array}{l}\text { PTCA- percutaneous transluminal coronary angioplasty; * residual } \\
\text { coronary stenosis }<50 \% \text { and TIMI } 2 \text { or } 3 \text { flow. }\end{array}$} \\
\hline
\end{tabular}


The greatest benefit regarding reduction in mortality was observed when this event was analyzed taking into consideration the Killip class on hospital admission (table IV). Patients referred for stenting had a lower incidence of Killip III/IV class on hospital admission as compared with the group treated with coronary angioplasty $(9.5 \%$ vs $14.6 \%, \mathrm{p}=0.0001)$. However, the greatest benefit with regard to reduction in immediate mortality was obtained only in the treatment of the Killip III/IV class patients (19.5\% vs 32.5\%, $\mathrm{p}=0.02$ ). Patients in Killip I/II class showed similar in-hospital mortality, either treated with stenting or only with primary coronary balloon angioplasty $(1.7 \%$ vs $2.8 \%, \mathrm{p}=0.9)$.

\section{Discussion}

Primary angioplasty performed within the first hours after an acute myocardial infarction is a well-known therapeutical method of coronary reperfusion applied with an increasing frequency in invasive cardiology centers ${ }^{1-6}$. Since its introduction, coronary angioplasty has been tested and its efficacy and safety have been proved from the first consecutive series until multicenter randomized and controlled studies were carried out ${ }^{1-6}$. In the direct comparison with the best thrombolytic regimen available, which is r-TPA intravenously administered for 90 minutes, primary coronary angioplasty showed advantages in reducing major events ${ }^{3}$. In a metaanalysis by Weaver et $\mathrm{al}^{5}$ of 2,606 patients analyzed, primary coronary angioplasty showed reduction in immediate mortality (more than 21 lives saved in 1,000 patients treated with coronary angioplasty vs r-TPA) and also in the combined occurrence of reinfarction and death (more than 46 lives saved without reinfarction in 1,000 patients treated). The incidence of hemorrhagic strokes was also much lower in those patients who underwent mechanical reperfusion $(0.1 \%$ vs $1.1 \%$, respectively, $\mathrm{p}=0.001)^{5}$.

The method, however, aims to optimize its results. The incidence of recurrent in-hospital ischemia after primary coronary angioplasty varies from $10 \%$ to $15 \%$, and, by 6 months, restenosis and reocclusion cause repetition of the angioplasty or surgical indication in as many as $35 \%$ of the patients ${ }^{7-10}$.

Stent implantation after acute myocardial infarction is a topic that generates increasing interest with the appearance of a number of comparative randomized studies on primary coronary balloon angioplasty. These studies aim to assess the immediate safety of the method and its late efficacy ${ }^{11-17}$.

\begin{tabular}{|lccc|}
\hline $\begin{array}{l}\text { Table IV - In-hospital mortality according to Killip class on } \\
\text { hospital admission and the respective treatment performed }\end{array}$ \\
\hline \multicolumn{4}{|c|}{ In-hospital mortality $(\%)$} \\
\hline Killip class & Stent & PTCA & $\mathrm{p}$ \\
\hline I/II & 1.7 & 2.8 & 0.9 \\
III/IV & 19.5 & 32.5 & 0.02 \\
\hline PTCA- percutaneous transluminal coronary angioplasty. \\
\hline
\end{tabular}

The CENIC registry comprises patients consecutively treated in several invasive cardiology centers in Brazil by different invasive cardiologists. This comparative analysis is not randomized and consists of a selection based on the cardiologist's indication, either based on an initial bad outcome of the primary coronary angioplasty (residual lesion $>30 \%$ or significant dissections) or even on primary indications aiming at better late results for the patient. The analysis of the results in this large sample of patients always draws attention as it represents the daily practice of interventional laboratories, different from the reality of planned randomized studies. Results of the data sent to the CENIC data processing center were assessed for all patients without any specific exclusion.

In this consecutive series of patients with data collected from 1996 to 1998 , we observed that the use of primary coronary angioplasty in acute myocardial infarction regularly accounted for $11 \%$ to $13 \%$ of the total coronary procedures reported to CENIC ${ }^{20}$. So, in 3,924 patients we could detect the significant exponential growth of stent implantation in acute myocardial infarction, which accounted for $20 \%$ of the procedures in 1996 and increased to $49 \%$ in 1998. This significant change is related to the daily evidence of good results obtained with stenting and the progressive publication of the randomized series ${ }^{11-17}$, therefore justifying the increased use of stents.

The data collection form sent to CENIC provides only the information related to the in-hospital phase but no information on the late follow-up. Analysis of the immediate inhospital results showed that stents were more frequently used than coronary balloon angioplasty in male patients with a previous infarction related to the anterior descending artery, the saphenous vein bypass grafts, and segmentary lesions. These results show the tendency of Brazilian cardiologists to favor the use of stents in the clinical and angiographic subgroups with the worst late outcomes when coronary balloon angioplasty is applied; elective randomized studies ${ }^{18,19}$ corroborate these results. Stenting had a higher success rate, but no significant difference was observed in regard to new emergency procedures, which had an incidence of $1 \%$. These values are lower than those of other series ${ }^{7}$, showing the low occurrence of in-hospital recurrent ischemia in our services, perhaps reflecting careful and optimized selection and results.

Reinfarction and global mortality were $50 \%$ lower with stenting. We demonstrated, however, that the greatest benefit in reducing death occurred in high-risk patients. Mortality for patients admitted to the hospital in Killip I/II class was very similar for both treatments (coronary angioplasty $=2.8 \%$ vs stenting $=1.7 \%, p=N S$ ). In the group of patients in Killip III/IV class, $15 \%$ of this series, mortality was reduced by $40 \%$ with stenting (coronary angioplasty = $32.5 \%$ vs stenting $=19.5 \%, \mathrm{p}=0.02$ ).

Some observations of the CENIC registry reproduced the findings of several randomized studies ${ }^{11-17}$. Since 1996, 5 multicenter studies have been conducted that randomized approximately 1,400 patients for stenting or balloon use in 
the acute phase of acute myocardial infarction. The ZWOLE $^{13}{ }^{13}$, FRESCO $^{14}$, GRAMI $^{15}$, STENTPAMI ${ }^{16}$ and PASTA ${ }^{17}$ studies showed similar conclusions. The in-hospital results of these studies showed no significant differences in regard to reduction in the occurrence of major events (reinfarction, stroke and death) and in regard to the success of the procedure. Success of coronary angioplasty was higher because of the possibility of stent implantation in the event of a poor initial outcome. This crossover between treatments was approximately $20 \%{ }^{13-16}$. The immediate mortality rates reported in these studies were in accordance with those observed in our registry. In randomized studies ${ }^{11-17}$, only the patients in Killip I/II class were included; this subgroup of patients did not show significant benefits in reducing mortality, which was also observed in the CENIC report. The mean immediate mortality of the randomized studies was $3 \%{ }^{11-17}$, very similar to our findings.

Reduction in coronary restenosis (stenting $=22 \%$ vs coronary angioplasty $=35 \%, \mathrm{p}=0.001$ ), as well as the lower need for new coronary revascularization procedures at the end of 6 months (stenting $=7.5 \%$ vs coronary angioplasty $=$ $17 \%, \mathrm{p}=0.001$ ), was very well established with the presentation of the results of the randomized STENT PAMI study, which has the most expressive randomization of patients (900) among all studies cited ${ }^{11-16}$.

In conclusion, the comparative analysis of the immediate results of coronary stenting in acute myocardial infarction or the use of primary coronary balloon angioplasty, based on consecutive registries of patients by CENIC, from 1996 to 1998, showed that stenting provides higher success rates, lower residual stenosis, and reduction in reinfarction and in in-hospital death. Patients selected for coronary balloon angioplasty were, more frequently, females with infarctions of inferior localization who, on hospital admission, were in a higher Killip class. However, the highest benefit with stenting was established in the high-risk subgroups, the mortality rate was reduced in Killip III/IV class patients, treatment of infarctions related to the anterior descending artery and of segmentary obstructive coronary lesions $(>10 \mathrm{~mm})$.

\section{Acknowledgments}

We thank the CENIC members and Dr. Ibraim M. F. Pinto for their support.

The following members of SBHCI took part in the national CENIC registry, from 1996 to 1998: Adnam Salmam,
Alberto Sottomayor, Alcides Zago, Aldo Duarte, Alexandre Azmuz, André Labrunie, André Pessanha, Angelo de Paola, Anselmo Salgado, Antenor Queiroga, Antenor Portela, Antônio Forte, Antônio Ferreira, Antônio Esteves F ${ }^{\circ}$, Antônio Godinho, Antônio Souza, Antônio Secches, Ari Mandil, Arthur Barreto, Carlos Zapata, Carlos Gottschall, Carlos Arêas, Carlos Cardoso, Carmine Scianni, Charles Vieira, Cláudia Alves, Clemente Greguolo, Constantino Constantini, Deborah Nercolini, Decio Salvadori, Edgar Victor, Edison Sandoval Peixoto, Ederval Kay, Edmur Araújo, Eduardo Nogueira, Eduardo Costa, Eduardo Nicolela, Elias Ayres Neto, Esmeralci Ferreira, Euler Mesquita, Evandro Osterne, Expedito Ribeiro, Fábio S. Brito Jr., Fausto Feres, Fernando Santana, Fernando DeVito, Flávio Leboute, Francisco Cardoso, Francisco Cruz, Francisco Stella, Frederico Silva, Galo Maldonado, Gilberto Nunes, Gilvan Dourado, Gustavo Alvarez, Haroldo Glavan, Heitor Carvalho, Hélio Castello Jr., Hélio Figueira, Itamar Oliveira, Ivan Lessa, James Glesser, Jamil Saad, João Batista Loures, João Lourenço Herrmann, João Otávio de Freitas, João Batista Guimarães, João Roberto Carvalho, Jorge Guimarães, Jorge Camargo Neto, Jorge Haddad, Jorge Buchler, José Malta Souza, José Antônio Jatene, José Marin Neto, José A. Mangione, José Augusto de Souza, José Augusto Rocha Araújo, José Gomes Fo , José Breno de Souza Filho, José Carlos Mello, José Carlos Brito, José Eduardo Sousa, José Henrique Mota, José Luiz Attab, José Maria Gomes, José Ribeiro de Souza, José Silvério Guimarães, José Tadeu Mourão, Júlio Cesar Andrea, Klerman Lopes, La Hore Rodrigues, Laio Oliveira, Lázaro Garcia, Lélio Silva, Léo Solarewicz, Leônidas Alvarenga Henriques, Luciano Abreu, Ludmilla Oliveira, Luis Maria Yordi, Luiz Alberto Mattos, Luiz Antônio Gubolino, Luiz Finzi, Luiz São Thiago, Luiz Bastos, Luiz Morrone, Luiz Kajita, Marcelo Cantarelli, Márcio Truffa, Márcio Silva, Marco Perin, Marcos Flávio Ribeiro, Marcus Gama, Mario Salles, Miguel Ratti, Milton M. Soares Neto, Milton Ferreira Filho, Murilo Furukawa, Nelson Mattos, Newton Stradler, Nilton Machado, Norberto Duda, Noriaki Takeshita, Paulo Jorge, Paulo Almeida, Paulo de Andrade, Paulo Sérgio de Oliveira, Pedro Horta, Pedro Beltrão, Pedro de Andrade, Pierre Labrunie, Raimundo de Melo, Raul Mora Júnior, Raul Hemb, Ricardo Barbosa, Rinaldo Carneiro, Roberto Bassan, Roberto Freire, Roberto Vieira, Roberto Pinna, Rodolfo Staico, Rogério Guimarães, Ronaldo Bueno, Ronaldo Villela, Salvador Cristovão, Salvador Borges Filho, Siguemituzo Arie, Theofanis Konstandinidis, Valter Lima, Vasco Muller, Vicente Mota, Virgílio Mares, Wilson Cecim Coelho. 


\section{References}

1. Grines CL, Browne KR, Marco J, et al. A comparison of primary angioplasty with thrombolytic therapy for acute myocardial infarction. N Engl J Med 1993; 328: 673-9.

2. Zijlstra F, DeBoer MJ, Hoorntje JCA, et al. A comparison of immediate coronary angioplasty with intravenous streptokinase in acute myocardial infarction. $\mathrm{N}$ Engl J Med 1993; 328: 680-4.

3. The Global Use of Strategies to Open Occluded Coronary Arteries in Acute Coronary Syndromes. A clinical trial comparing primary coronary angioplasty with tissue plasminogen activator for acute myocardial infarction. N Engl J Med 1997; 336: 1621-8

4. Ribeiro EE, Silva L, Carneiro R, et al. Randomized trial of direct angioplasty versus intravenous streptokinase in acute myocardial infarction. J Am Coll Cardiol 1993; 22: 376-80.

5. Weaver WD, Simes J, Betriu A, et al. Comparison of Primary Coronary Angioplasty and Intravenous Thrombolytic Therapy for Acute Myocardial Infartion. JAMA 1997; 278: 2093-8.

6. Mattos LA, Cano MC, Maldonado G, et al. Emprego da angioplastia coronária no infarto agudo do miocárdio sem o uso prévio de agentes trombolíticos. Análise de 201 pacientes. Arq Bras Cardiol 1990; 55: 279-86.

7. Stone GW, Grines CL, Browne KF, et al. Implications of recurrent ischemia after reperfusion therapy in acute myocardial infarction: a comparison of thrombolytic therapy and primary angioplasty. J Am Coll Cardiol 1995; 26: 66-72.

8. Stone $\mathrm{GW}$, Marsalese $\mathrm{D}, \mathrm{Brodie} \mathrm{BD}$, et al. A prospective, randomized evaluation of prophylatic intraaortic balloon couterpulsation in high-risk patients with acute myocardial infarction. J Am Coll Cardiol 1997; 29: 1459-67.

9. Brodie BR, Grines CL, Ivanhoe R, et al. Six-month clinical and angiographic follow-up after direct angioplasty for acute myocardial infarction. Circulation 1994; 25: 156-62.

10. Mattos L, Feres F, Abizaid A, et al. Repeat Revascularizations procedures after primary PTCA for acute myocardial infarction: an angiographic follow-up. Circulation 1996; 94: I-330.

11. Serruys PW, Grines CL, Stone GW, et al. Stent Implantation in acute myocardial infarction using a heparin-coated stent: a pilot study as a preamble to a randomi- zed trial comparing balloon angioplasty and stenting. Int. J. Cardiovasc Interventions 1998; 1: 19-27.

12. Stone GW, Brodie BR, Griffin JJ, et al. Prospective, multicenter study of the safety and feasibility of primary stenting in acute myocardial infarction: In-hospital and 30-day results of the PAMI Stent Pilot Trial. J Am Coll Cardiol 1998; 31: 23-30.

13. Suryapranata H, Vant Hoff AWJ, Hoorntje JCA, et al. Randomized comparison of coronary stenting with balloon angioplasty in selected patients with acute myocardial infarction. Circulation 1998; 97: 2502-5.

14. Antoniucci D, Santoro G, Bolognese L, et al. A clinical trial comparing primary stenting of the infarct-related artery with optimal primary angioplasty for acute myocardial infarction. Results form the Florence Randomized Elective Stenting in Acute Coronary Occlusions (FRESCO) trial. J Am Coll Cardiol 1998; 31: 1234-9.

15. Rodriguez A, Bernardi V, Fernandez M, et al. In-hospital and late results of coronary stents versus conventional balloon angioplasty in acute myocardial infarction (GRAMI trial). Am J Cardiol 1998; 81: 1286-91.

16. Grines CL, Cox D, Garcia E, et al. Stent PAMI: Primary endpoint results of a multicenter randomized trial of heparin coated stenting vs. primary PTCA for AMI. Circulation 1998; 98: I-22.

17. Saito S, Hosokawa HS, Nakamura S, et al. Primary stent implantation is superior to balloon angioplasty in acute myocardial infarction - The result of Japanese PASTA (Primary Angioplasty versus Stent Implantation in Acute Myocardial Infarction) trial. J Am Coll Cardiol 1997; 29: 390(A).

18. Serruys PW, Van Hout B, Bonnier H, et al. Randomized comparison of implantation of heparin-coated stents with balloon angioplasty in selected patients with coronary artery disease. Lancet 1998; 352: 673-81.

19. The EPISTENT investigators. Randomized placebo-controlled and balloon angioplasty controlled trial to assess safety of coronary stenting with use of platelet glycoprotein IIb/IIIa blockade. Lancet 1998; 352: 87-92.

20. Sousa AGMR, Mattos LA, Moura Campos Neto C, et al. Intervenções coronárias percutâneas para revascularização no Brasil em 1996 e 1997, comparadas as do biênio 1992 e 1993. Relatório do Registro CENIC (Central Nacional de Intervenções Cardiovasculares). Arq Bras Cardiol 1998; 70: 423-30. 